\title{
Transgender Women's Drug Use in the Dominican Republic
}

Henna Budhwani, ${ }^{1, *}$ Kristine R. Hearld, ${ }^{1}$ Adrienne N. Milner, ${ }^{2}$ Elaine McGlaughlin, ${ }^{3}$ Rebecca Charow, Rosa Mayra Rodriguez-Lauzurique, ${ }^{4}$ Santo Rosario, ${ }^{5}$ and Robert Paulino-Ramirez ${ }^{4,5}$

\begin{abstract}
Purpose: Studies on drug use in transgender populations, particularly those in resource-limited settings, are scarce. Considering that drug use can be a coping mechanism to deal with stigma and traumatic experiences, we examined associations between stigma, trauma, and drug use in a national sample of transgender women from the Dominican Republic.

Methods: Bivariate analyses examined differences between drug users and abstainers $(n=287)$. Multivariate analyses reported odds ratios (OR) with general drug, marijuana, and cocaine use as outcomes $(n=243)$.

Results: A quarter of respondents (24.5\%) experienced sexual abuse, $12.1 \%$ were tortured, and $20.1 \%$ experienced a murder attempt. More than a quarter reported using illegal drugs (26.1\%). Drug users had lower socioeconomic status; $30.0 \%$ of drug users had a primary level of education or less (18.2\% of abstainers) and $17.6 \%$ of drug users had higher income, defined as greater than 10,001 pesos ( $\$ 210$ United States Dollars, USD) per month (28.1\% of abstainers). More than half of drug users experienced some form of trauma (51.4\%) compared to $43.5 \%$ of abstainers, and $28.4 \%$ of drug users, compared to $17.1 \%$ of abstainers, experienced a murder attempt on her life. Independent sample $t$-tests found significant differences between drug users and abstainers. Transgender women who experienced sexual abuse had three times high odds of using cocaine. Drug users were more likely to have experienced sexual abuse and attempted suicide ( $p<0.05$ for both). Respondents who attempted suicide had higher odds of using drugs generally and using marijuana specifically, compared to respondents who had not attempted suicide $(\mathrm{OR}=2.665$ and 3.168 , respectively). Higher scores on the stigma scale were associated with higher odds of any drug use and cocaine use (OR=1.132 and 1.325, respectively).

Conclusions: Although some nations have implemented antidiscrimination policies protecting transgender citizens, these policies are not consistently enforced. Eliminating stigma and stigmatizing policies may reduce rates of drug use as a coping mechanism.
\end{abstract}

Keywords: Dominican Republic; drug use; stigma; transgender women

\section{Introduction}

Globally, transgender women are economically marginalized, experience hostility in the communities in which they reside, and are more likely to engage in high-risk behaviors, particularly those associated with HIV and sexually transmitted infections compared to other women. ${ }^{1-7}$ These negative exposures and experiences are exacerbated in resource-limited settings where nontraditional gender identities are vehemently rejected, resulting in transgender women being overtly ostracized. ${ }^{8}$ Experiencing this kind of stigma and discrimination is associated with coping

\footnotetext{
${ }^{1}$ University of Alabama at Birmingham, Birmingham, Alabama.

${ }^{2}$ Queen Mary University of London, London, United Kingdom.

${ }^{3}$ United Nations Family Planning Association (UNFPA), Tegucigalpa, Honduras.

${ }^{4}$ Institute for Tropical Medicine and Global Health, Universidad Iberoamericana, Santo Domingo, República Dominicana.

${ }^{5}$ Centro de Orientación e Investigación Integral (COIN), Santo Domingo, Dominican Republic.
}

*Address correspondence to: Henna Budhwani, PhD, MPH, Health Care Organization and Policy, University of Alabama at Birmingham, 310 Ryals Public Health Building, 1665 University Boulevard, Birmingham, AL 35294, E-mail: budhwani@uab.edu 
mechanisms such as drug use, alcohol consumption, and engagement in high-risk sexual behaviors ${ }^{9,10}$; these risk behaviors can be intensified in transgender women, those with lower socioeconomic status, and in those living in resource-poor settings. ${ }^{11}$ Moreover, in the Dominican Republic where one-third of transgender women believe it is difficult to access healthcare services due to stigma and shame, the likelihood of engaging in mental healthcare for substance use is severely reduced. ${ }^{5,9}$ Considering the socially precarious environment affecting transgender women residing in the Dominican Republic, we examined these women's drug use patterns to better understand these behaviors and their associates in such a hard-to-reach population.

Globally, 246 million people use illicit drugs, and 27 million have a drug use disorder or dependence. ${ }^{12,13} \mathrm{In}$ 2013, there were 187,100 drug-related deaths reported worldwide. ${ }^{12}$ In Latin America and the Caribbean, the drug-related mortality rate is 18.4 per million, ${ }^{12}$ with cocaine being the primary drug of concern in the Caribbean. ${ }^{12}$ In the Dominican Republic, powder cocaine, crack cocaine, heroin, and marijuana are used at particularly high rates. ${ }^{14}$ In fact, after only 1 year and 3 months of operation, the Joint Airport Interdiction Task Forces in Santo Domingo and Punta Cana seized $227 \mathrm{~kg}$ of cocaine, $11 \mathrm{~kg}$ of heroin, $1.1 \mathrm{~kg}$ of marijuana, and $\$ 763,000$ USD in $2016 .{ }^{15}$ These high confiscation rates not only indicate the amount of drugs available in the Dominican Republic but also reflect that the Dominican Republic is a transit country for trafficking drugs to other destinations. ${ }^{15}$ Although, the Dominican Republic's National Statistical Office does not have a formal surveillance and reporting system for drug use and drug-related deaths, ${ }^{16}$ other sources estimated $2.3 \%$ of men and $0.6 \%$ of women in the Dominican Republic are drug users. $^{2}$ In addition, the Inter-American Drug Abuse Control Commission estimated there to be $\sim 2000$ heroin users in the Dominican Republic based on a study published jointly by its Inter-American Observatory on Drugs and the National Drug Council of the Dominican Republic. ${ }^{17}$ Although this study did not focus on injectable drugs, such as heroin, injectable drug use patterns in the Dominican Republic are particularly relevant to drug studies in the Caribbean, since injectable drug use is on the rise in the Dominican Republic. ${ }^{18-20}$ Moreover, this alarming uptick has been attributed to the social importation of injectable drug use behavior from residents (e.g., deportees from the United States) who lived outside of the country, but who have returned or who maintain connections to industrialized nations. ${ }^{18-20}$

In addition, according to the most recent report by the Dominican Republic's National Council for HIV and AIDS (CONAVIHSIDA), those who identify as men who has sex with men (MSM) or transgender women reported significantly higher drug use than the general population. ${ }^{2}$ Among Santo Domingobased MSM and transgender women, the most commonly used illegal drugs were marijuana (60.0\%), cocaine $(24.9 \%)$, and crack cocaine $(13.3 \%){ }^{2}$ In a small mixed-methods study examining drug use patterns among transgender female sex workers, $65 \%$ tested positive for recent drug use and more than half of the sample $(52.8 \%)$ considered themselves to be at "high risk" of becoming addicted to drugs, ${ }^{21}$ in part, due to the deleterious social forces affecting transgender women in high-stigma settings. Although research on substance use rarely reports sexual orientation or gender identity, and the majority of studies that do are focused on HIV risk rather than drug use, ${ }^{22}$ some studies suggest higher prevalence of alcohol and drug use in transgender women compared with the general population and a strong association between psychosocial risk factors and substance use. ${ }^{10,20}$ Again, primary reasons for drug use in transgender populations are to cope with transphobia, discrimination, violence, stressful life events, and stigma. ${ }^{10,23-25}$

The injurious effects of stigma are well documented; stigma is linked to risk behaviors and coping mechanisms, such as drug use. ${ }^{26-28}$ Stigma is fundamentally social in which one group of people (such as transgender women) is labeled as deviant, and perpetually discredited because of their characteristics or behaviors. ${ }^{26,29}$ Because stigma positions one group as inherently inferior or less valid according to the perspective of another, dominant group, stigma manifests and is reproduced throughout social structures and during interpersonal interactions. ${ }^{26,27}$ Theoretically speaking, there are three realms of stigma-perceived stigma, enacted stigma, and internalized stigma. ${ }^{28,30}$ Perceived stigma refers to an individual's subjective awareness of discriminatory attitudes from other people or society at large; enacted stigma is an individual's lived experience of negative treatment; and internalized stigma refers to an individual developing negative beliefs about him or herself as a result of accepting the repeated disparaging views of others. ${ }^{28,30}$ It is precisely this type of social rejection that encourages transgender women to engage in coping behaviors such as drug use and avoid seeking 
mental health and drug use treatment services, among others. $^{9,27}$

Considering the dearth of research on the drug use patterns of transgender women who reside in resourcelimited settings, our study is particularly novel. Findings from this work have the potential to inform public health programs and policy designed to reduce drug use in transgender women not only in the Dominican Republic but also in similar settings across the Caribbean and Latin America. In view of prior research on stigma, drug use, and coping behaviors in transgender women, we hypothesized that stigma and trauma would be associated with drug use in transgender women residing in the Dominican Republic.

\section{Methods}

Data for this study are from the 2015 Dominican Republic Transgender Health Needs Study (THNS), collected by Centro de Orientación e Investigación Integral (COIN) and funded by the National Council for HIV and AIDS (CONAVIHSIDA) representing the Dominican Republic Ministry of Health. Facilitated interviews with transgender women were employed to collect quantitative survey data. Transgender women who self-identified with a biological sex as male and presented and identified with a gender of woman, met the inclusion criteria. Transgender communitybased organization leaders from Trans Amigas Siempre Amigas, Coalicion de Mujeres Trans, Trasvesti y Transexuales Trabajadores Sexuales, and Trans Este Podemos Avanzar were engaged in design, validation, and implementation of this questionnaire. The questionnaire was previously implemented in Central American countries to measure the health needs of their transgender populations, and was adapted to the linguistic Spanish dialect of the Dominican Republic. Data were collected on the following: demographics, sex partners, sexual history, use of condoms and lubricants, sexually transmitted Infections, healthcare utilization, gender-based violence, stigma and discrimination, use of hormones and other feminization processes, social inclusion/isolation, and stress.

As recommended by the Joint United Nations Programme on HIV/AIDS (UNAIDS), this study leveraged the PLACE method of data collection. Specifically, snowball sampling using peers from the different communities was employed. Data were collected from transgender women in Santo Domingo, La Altagracia, Puerto Plata, Santiago, Dajabón, Independencia, and Barahona. Site selection was informed by the Ministry of Health's internal surveillance data on locations where the most-at-risk for HIV infection are located and included the United States President's Emergency Plan for AIDS Relief s (PEPFAR) priority provinces. Interviews were conducted in neutral spaces, such as restaurants and parks, recommended by the local transgender community and community-based organizations working in study communities.

Ethical approval for the study was provided by El Consejo Nacional de Bioética en Salud (CONABIOS) in the Dominican Republic, and informed consent was collected verbally as verbal consent is a modality often used in participatory action research when working with reported low-literacy populations. ${ }^{31,32}$ It has been found that when verbal consent is designed and implemented thoughtfully, it leads to voluntary participation and thorough comprehension of the study. Written consent, on the other hand, may cause psychosocial discomfort when the respondent cannot read or write. ${ }^{33,34}$ The verbal consent process we employed involved three steps: (1) provision of a thorough verbal description about the participant's rights and the study purpose in simple language, (2) an explanation of topic covered, and (3) request of verbal consent that she is participating freely, without coercion. The verbal consent was witnessed by a senior investigator. The University of Alabama at Birmingham's Institutional Review Board provided ethical approval for secondary data analysis (No. N150803004).

\section{Dependent variable}

Drug use was measured through the prompt and question, "Now we are going to talk about the use of drugs and alcohol. I am going to read a list, please, indicate in what frequency you used each drug in the past 6 months." The list included marijuana, cocaine, crack, heroin, injectable drugs, inhalant drugs (glue and thinner), amphetamines (pills), and ecstasy. Responses included the following: "daily," "one time a week," "multiple times a month," "multiple times during the past 6 months," and "I don't use this." Because of low affirmative response rates on the majority of drugs listed, three dummy dependent variables are utilized in the study: whether the respondent has used (1) any drugs, (2) marijuana, or (3) cocaine, in the past 6 months $(1=$ yes; $0=$ no).

\section{Independent variables}

Three demographic variables were included in the analysis: age, income, and educational attainment were 
included as controls. Age was measured as a continuous variable in years. Monthly income in pesos was measured as a categorical variable $(1=0-1000(\sim \$ 0-\$ 21$ USD); $2=1001-5000$ ( $\sim \$ 21-\$ 105$ USD); $3=5001-$ 10000 ( $\sim \$ 105-\$ 210$ USD); and $4=$ more than 10,001 (more than \$210 USD per month) pesos). As a point of reference, minimum wage in the Dominican Republic is about 11,400 pesos per month, or about \$241 USD. Educational attainment was measured using three dichotomous variables: primary school or less [referent], secondary school, or postsecondary school (technical school or university).

Trauma was measured with four dichotomous variables of whether the respondent since the age of $14 \mathrm{had}$ experienced (1) sexual abuse, (2) psychological abuse, (3) torture, and (4) if someone had attempted to kill the respondent (yes $=1 ; 0=$ no). Attempted suicide was a dichotomous variable representing whether or not respondents answered affirmatively to the question, "Have you attempted suicide?" $(1=$ yes; $0=$ no). Stigma was measured on a $0-9$ scale (Cronbach's $\alpha=0.827$ ) and measured how many times in the past 3 months the respondent had experienced the following events, specifically due to the fact that [she] is a trans person: (1) arguments between her parents, (2) problems with her brothers or sisters, (3) arguments between her and her parents, (4) arguments with other family members, (5) problems with her professors or bosses, (6) problems with classmates or coworkers, (7) arguments or disagreements with close friends, (8) lost close friendships, and (9) problems with the police or other authorities. Family Health International (FHI) originally employed this stigma scale during their 2012 National Surveillance Study conducted in the Dominican Republic. These measures were originally developed for use with men who have sex with men (MSM, which was the broad category within which transgender women were classified previously), and were therefore adjusted during the pilot testing phase of this study for acceptability among transgender populations.

\section{Statistical analyses}

In addition to completing univariate and bivariate analyses $(n=287)$, we employed multivariate analysis using logistic regression. Listwise deletion was utilized, and outcomes were (1) any drug use $(n=240)$, (2) marijuana use $(n=243)$, and (3) cocaine use $(n=242)$. All analyses were conducted in IBM SPSS Statistics 24.

\section{Results}

Descriptive statistics

Univariate and bivariate statistics are reported in Table 1. The average age of our sample was 26.1 years with those who used drugs in the past 6 months being slightly older (26.6) than those who had not (25.9). Approximately a quarter of respondents had a monthly income of over 10,000 pesos (\$210 USD) per month, meaning three-quarters of respondents had an income under the Dominican Republic's minimum wage level. Roughly $21 \%$ of the sample had a primary school education or less. More than a quarter of the sample had used drugs in the past 6 months (26.1\%). $21.5 \%$ of the sample had used marijuana and $10.5 \%$ had used cocaine.

Table 1. Descriptive Statistics for Study Variables

\begin{tabular}{|c|c|c|c|c|}
\hline Variable & $\begin{array}{l}\% \text { of sample } \\
(n=287)\end{array}$ & $\begin{array}{l}\% \text { of drug users } \\
\quad(n=75)\end{array}$ & $\begin{array}{l}\% \text { of nondrug users } \\
\quad(n=212)\end{array}$ & $t(\mathrm{df})$ \\
\hline Used drugs & 26.1 & 100.0 & 00.0 & - \\
\hline Cocaine & 10.5 & 38.7 & - & - \\
\hline Marijuana & 21.5 & 78.7 & - & - \\
\hline Inhaled drugs & 2.0 & 6.7 & - & - \\
\hline Crack & 1.4 & 5.3 & - & - \\
\hline Other (e.g., heroin and ecstasy) & 4.4 & 5.6 & - & - \\
\hline Experienced trauma & 45.6 & 51.4 & 43.5 & $1.157(272.000)$ \\
\hline Sexual abuse & 24.5 & 36.0 & 20.3 & $2.516(113.434)^{*}$ \\
\hline Psychological abuse & 32.2 & 32.0 & 32.2 & $-0.034(281.000)$ \\
\hline Torture & 12.1 & 16.0 & 10.7 & $1.114(114.073)$ \\
\hline Attempted murder & 20.1 & 28.4 & 17.1 & $1.917(111.451)$ \\
\hline Attempted suicide & 21.3 & 32.0 & 17.5 & $2.417(110.270)^{*}$ \\
\hline Five or greater on stigma scale & 34.1 & 42.9 & 30.9 & $1.751(115.402)$ \\
\hline Income (> 10,001 pesos/month) & 25.3 & 17.6 & 28.1 & $-1.924(151.238)$ \\
\hline Education (primary or less) & 21.2 & 30.0 & 18.2 & $1.931(111.600)$ \\
\hline Mean age & 26.1 & 26.6 & 25.9 & $0.694(285.000)$ \\
\hline
\end{tabular}

${ }^{*} p<0.05$. 
We found a high level of trauma present in our sample. Almost half (45.6\%) of respondents experienced some form of trauma; $24.5 \%$ experienced sexual abuse, $32.2 \%$ experienced psychological abuse, $12.1 \%$ were tortured, and $20.1 \%$ experienced a murder attempt on her life. The rate of trauma (any of the four types) was higher $(51.4 \%)$ in those who had used drugs compared to those who had not (43.5\%). However, when examining the statistical effects of each trauma indicator individually, independent sample $t$ tests showed only significant differences between drug users and abstainers in terms of experiencing sexual abuse $(p<0.05)$

Almost a quarter of the sample $(21.3 \%)$ reported attempting suicide and more than a third of the sample scored a five or greater on the stigma scale (34.1\%). Drug users were also more likely to have attempted suicide than abstainers $(p<0.05)$.

\section{Multivariate analyses}

In terms of the trauma measures, experiencing psychological abuse was associated with lower odds of any drug use (odds ratio $[\mathrm{OR}]=0.423, p<0.05$, confidence interval $[95 \% \mathrm{CI}]=0.187-0.955)$. However, experiencing sexual abuse was associated with over three times greater odds of cocaine use $(\mathrm{OR}=3.381, p<0.05,95 \%$ $\mathrm{CI}=1.069-10.688$ ). Transgender women who had attempted suicide had over two and a half times greater odds of any drug use $(\mathrm{OR}=2.665, p<0.05,95 \%$ $\mathrm{CI}=1.165-6.096)$ and over three times greater odds of using marijuana $(\mathrm{OR}=3.168, p<0.01,95 \% \mathrm{CI}=1.361-$ 7.370 ), but not cocaine use. In contrast, experiencing stigma was associated with higher odds of cocaine use $(\mathrm{OR}=1.270, p<0.01,95 \% \mathrm{CI}=1.068-1.510)$, but not any drug use or marijuana use.

The only demographic variable significantly related to drug use was having a postsecondary education. Having a postsecondary education was associated with lower odds of using any drugs $(\mathrm{OR}=0.268, p<0.05$, $95 \% \mathrm{CI}=0.085-0.846)$ and marijuana $(\mathrm{OR}=0.235$, $p<0.05,95 \% \mathrm{CI}=0.069-0.798)$ compared to women with a primary school education or less (Table 2).

\section{Discussion}

Our findings highlight basic drug trends in transgender women residing in the Dominican Republic. First, rates of trauma and negative exposures were high in our sample. For example, more than a quarter of respondents (26.1\%) were illicit drug users. Although this seems alarming compared to the $9.4 \%$ of the adult American population that admits to using illegal drugs, over $30 \%$ of American gender and sexual minorities use drugs such as marijuana or cocaine, which is close to the rate we found in our sample from the Dominican Republic. ${ }^{35,36}$ We hypothesized that stigma and trauma would be associated with drug use in our sample and found some support. Drug users had higher rates of trauma than abstainers. Specifically, drug users had higher rates of experienced sexual abuse, torture, and having experienced a murder attempt. This held true in the multivariate analyses with sexually abused respondents having higher odds of drug use. The rates of attempted suicide and stigma were higher for drug users compared to abstainers, and significant associations

Table 2. Odds Ratios for Logistic Regression of Drug Use

\begin{tabular}{|c|c|c|c|c|c|c|}
\hline \multirow[b]{2}{*}{ Variables } & \multicolumn{2}{|c|}{ Any drug usage } & \multicolumn{2}{|c|}{ Marijuana } & \multicolumn{2}{|c|}{ Cocaine } \\
\hline & OR & $95 \% \mathrm{Cl}$ & OR & $95 \% \mathrm{Cl}$ & OR & $95 \% \mathrm{Cl}$ \\
\hline \multicolumn{7}{|l|}{ Experienced trauma } \\
\hline Sexual abuse & 1.948 & $0.847-4.478$ & 1.326 & $0.541-3.250$ & $3.381^{*}$ & $1.069-10.688$ \\
\hline Psychological abuse & $0.423^{*}$ & $0.187-0.955$ & 0.576 & $0.249-1.332$ & 0.484 & $0.155-1.512$ \\
\hline Torture & 0.754 & $0.261-2.176$ & 0.529 & $0.169-1.652$ & 1.666 & $0.450-6.169$ \\
\hline Attempted murder & 1.126 & $0.452-2.802$ & 1.211 & $0.472-3.108$ & 0.899 & $0.232-3.474$ \\
\hline Attempted suicide & $2.665^{*}$ & $1.165-6.096$ & $3.168^{* *}$ & $1.361-7.370$ & 0.899 & $0.263-3.079$ \\
\hline Stigma scale & 1.112 & $0.989-1.249$ & 1.051 & $0.930-1.188$ & $1.270^{* *}$ & $1.068-1.510$ \\
\hline Monthly income & 0.921 & $0.662-1.279$ & 0.864 & $0.609-1.226$ & 1.125 & $0.692-1.829$ \\
\hline \multicolumn{7}{|l|}{ Education } \\
\hline Secondary school & 1.210 & $0.582-2.516$ & 0.877 & $0.417-1.847$ & 1.779 & $0.590-5.363$ \\
\hline Postsecondary & $0.268^{*}$ & $0.085-0.846$ & $0.235^{*}$ & $0.069-0.798$ & 0.179 & $0.018-1.765$ \\
\hline Age & 1.011 & $0.977-1.047$ & 0.987 & $0.948-1.027$ & $1.046^{*}$ & $1.001-1.092$ \\
\hline Pseudo $R^{2}$ & 0.131 & & 0.102 & & 0.124 & \\
\hline$n$ & 240 & & 243 & & 242 & \\
\hline
\end{tabular}

${ }^{* *} p<0.01,{ }^{*} p<0.05$.

$\mathrm{Cl}$, confidence interval; OR, odds ratio. 
between these variables and drug use were evident in the multivariate analysis with suicide attempters having higher odds of using drugs in general and specifically marijuana, and respondents who scored higher on the stigma scale had higher odds of using cocaine.

Extending our findings to inform policy, we noted that the current regulatory framework in the Dominican Republic does not consider drug use to be a public health issue and has two important implications. First, Article 7 of Law $50-88$ on drugs and controlled substances severely penalizes both users and dealers/traffickers; it does not distinguish between users and dealers/traffickers for nonhallucinogenic substances and opium and its derivatives, meaning that those who use drugs are prosecuted in the same way and possibly receive the same extent of punishment as those who supply and transport illicit drugs. In a country that holds such deep stigma toward transgender populations, this law could severely disadvantage transgender women charged with drug use and tried in a court of law, or could also encourage those who are recreational users to "deal" drugs, since there is no additional penalty for doing so. Second, by criminalizing drug use with the same severity as drug dealing-emphasizing the criminal nature of the offense-rather than framing it as a public health challenge, those who are charged with drug-related offenses are not viewed as ill or in need to treatment, but rather as a threat to civil society, which could exacerbate the stigma transgender women face in the Dominican Republic.

Furthermore, a legal barrier exists for accessing treatment services, as well as limits treatment center resources since they are unable to use low-dose opiumbased substances to wean patients off their use. ${ }^{17,37}$ While a dialogue on harm and risk reduction practices is gaining ground in the Dominican Republic as evidenced by the sixth Latin American and first Caribbean Conference on Drug Policy in Santo Domingo in October, 2016, and by the negotiation of a pilot study with the University of Puerto Rico on medically assisted treatment programs for intravenous drug users, the current official orientation toward drug use is prohibitionist and punitive. Culturally, drug use is more commonly viewed as a moral shortcoming than a medical issue. ${ }^{38}$

Limitations should be carefully considered when applying findings. First, bias is expected in self-reported, survey data, especially when the population is stigmatized with lower levels of socioeconomic status, such as transgender women in the Dominican Republic. In addition, some of our measures lacked specificity, re- ducing extensibility of our findings. Certain terms, such as torture, were not defined; thus, respondents were left to interpret the meaning of these words. Also, although our sample was collected nationwide, the final sample size was small; more comprehensive data collection could provide deeper insight. Finally, causality cannot be inferred from cross-sectional data. Future studies should consider our limitations when designing and implementing subsequent studies with this same population.

\section{Conclusion}

Globally, transgender women are traumatized, stigmatized, and stripped of their human rights. Although progress has been made to support transgender rights in some high-income nations, this advancement has not occurred universally in resource-poor settings. ${ }^{38}$ The transgender community continues to be traumatized at high rates, which robs transgender persons of respect and dignity and has detrimental effects on physical health, mental health, and social well-being., ${ }^{89-42}$

\section{Acknowledgments}

The authors would like to acknowledge the hard work of the Centro de Orientación e Investigación Integral's (COIN), UNIBE School of Medicine, and the support of the University of Alabama at Birmingham (UAB) Sparkman Center for Global Health.

\section{Authors' Contributions}

H.B. conceptualized and developed this study. H.B., K.R.H., A.N.M., R.C., and E.M. all contributed to the writing. A.N.M. and K.R.H. conducted the statistical analyses. R.P.-R. and R.M.R.-L. were the original study investigators. S.R. contracted with R.P.-R and R.M.R.L. to conduct this study through his community-based organization.

\section{Author Disclosure Statement}

No competing financial interests exist.

\section{References}

1. Brennan J, Kuhns LM, Johnson AK, et al. Syndemic theory and HIV-related risk among young transgender women: the role of multiple, co-occurring health problems and social marginalization. Am J Public Health. 2012;102:1751-1757.

2. CONAVIHSIDA. Segunda Encuesta de Vigilancia de Comportamiento con Vinculación Serológica en Poblaciones Claves. 2012. http://countryoffice .unfpa.org/dominicanrepublic/drive/CONAVIHSIDASegundaEncuesta Vigiliancia.pdf Accessed July 6, 2017.

3. Kussin-Shoptaw AL, Fletcher JB, Reback CJ. Physical and/or sexual abuse is associated with increased psychological and emotional distress among transgender women. LGBT Health. 2017;4:268-274. 
4. Nemoto T, Bödeker B, Iwamoto M. Social support, exposure to violence and transphobia, and correlates of depression among male-to-female transgender women with a history of sex work. Am J Public Health. 2011;101:1980-1988.

5. Bockting W, Holloway J, Keatley J, et al. Blueprint for the provision of comprehensive care for trans persons and their communities in the Caribbean and other Anglophone countries. www.paho.org/hq/index .php?option=com_docman\&task=doc_view\&gid=28440\&lang=en\& Itemid=270 Accessed July 6, 2017.

6. Perez-Brumer AG, Reisner SL, McLean SA, et al. Leveraging social capital: multilevel stigma, associated HIV vulnerabilities, and social resilience strategies among transgender women in Lima, Peru. J Int AIDS Soc. 2017;20:1-8.

7. Tebbe EA, Moradi B. Suicide risk in trans populations: an application of minority stress theory. J Couns Psychol. 2016;63:520-533.

8. Winter S, Diamond M, Green J, et al. Transgender people: health at the margins of society. Lancet (London, England). 2016;388:390-400.

9. Hasbún J. Diversity and commonality-a look at female and transgende sex workers in three Caribbean countries. 2012. www.cvccoalition.org/ sites/default/files/SEX_WORKERS_BASELINE_STUDYsmallpdf_com.pdf Accessed July 6, 2017.

10. Reback CJ, Fletcher JB. HIV Prevalence, substance use, and sexual risk behaviors among transgender women recruited through outreach. AIDS Behav. 2014;18:1359-1367.

11. Galea S, Ahern J, Vlahov D. Contextual determinants of drug use risk behavior: a theoretic framework. J Urban Health. 2003;80(4 Suppl 3):iii50-iii58.

12. United Nations Office on Drugs and Crime (UNODC). World Drug Report 2015.United Nations Sales No. E.15.XI.6. Vienna. 2015. www.unodc.org/ documents/wdr2015/World_Drug_Report_2015.pdf Accessed April 3, 2017.

13. Uchtenhagen A. Substance Use Problems in Developing Countries. World Health Organization, 2004. www.who.int/bulletin/volumes/82/9/ editorial20904html/en Accessed April 3, 2017.

14. Padilla MB, Guilamo-Ramos V, Godbole R. A syndemic analysis of alcoho use and sexual risk behavior among tourism employees in Sosúa, Dominican Republic. Qual Health Res. 2012;22:89-102.

15. UNODC. Strengthening of Airport Interdiction Operations in the Dominican Republic in the Framework of the EU Funded AIRCOP Project. 2017. www.unodc.org/ropan/en/strengthening-of-airport-interdictionoperations-in-the-dominican-republic-in-the-framework-of-the-eufunded-aircop-project.html Accessed July 6, 2017.

16. (ONE) ON de E. Compendio de Estadísticas de Muertes Accidentales Y Violentas, 2006-2014. 2016. www.ema.europa.eu/ema Accessed April 3, 2017.

17. Inter-American Drug Abuse Control Commission (CICAD). Report on Drug Use in the Americas, 2015. 2015. www.cicad.oas.org/oid/pubs/ DrugUseAmericas_ENG_web.pdf Accessed April 3, 2017.

18. Inter-American Drug Abuse Control Commission CICAD. Organization of American States (OAS). Report on Drug Use in the Americas. 2015.

19. World Health Organization (WHO). Atlas of Substance Use Disorders Resources for the Prevention and Treatment of Substance Use Disorders-Dominican Republic Country Profile. 2010.

20. UN Office for Drug Control and Crime Prevention (UNODCCP). Fact Sheet-Heroin in the Caribbean Region. 2002.

21. COTRAVED. Study of Drug Use Patterns and Healthcare Access Among Transgender Female Sex Workers (Tgsw) in the Dominican Republic. 2014.

22. Flentje A, Bacca CL, Cochran BN. Missing data in substance abuse research? Researchers' reporting practices of sexual orientation and gender identity. Drug Alcohol Depend. 2015;147:280-284.

23. Keuroghlian AS, Reisner SL, White JM, Weiss RD. Substance use and treatment of substance use disorders in a community sample of transgender adults. Drug Alcohol Depend. 2015;152:139-146.

24. Hotton AL, Garofalo R, Kuhns LM, Johnson AK. Substance use as a mediator of the relationship between life stress and sexual risk among young transgender women. AIDS Educ Prev. 2013;25:62-71.

25. Wilson EC, Chen Y-H, Arayasirikul S, Wenzel C, Raymond HF. Connecting the dots: examining transgender women's utilization of transition-related medical care and associations with mental health, substance use, and HIV. J Urban Health. 2015;92:182-192.

26. Turan B, Budhwani H, Fazeli PL, et al. How does stigma affect people living with HIV? The mediating roles of internalized and anticipated HIV stigma in the effects of perceived community stigma on health and psychosocial outcomes. AIDS Behav. 2017;21:283-291.

27. Link BG, Phelan JC. Stigma and its public health implications. Lancet. 2006;367:528-529.
28. Phillips KD, Moneyham L, Tavakoli A. Development of an Instrument to Measure Internalized Stigma in Those with HIV/AIDS. Issues Ment Health Nurs. 2011;32:359-366.

29. Goffman E. Stigma: Notes on the Management of Spoiled Identity. Simon \& Schuster, 1986. https://books.google.com.do/books?hl=en\&lr=\&id= zuMFXuTMAqAC\&oi=fnd\&pg=PA1\&dq=goffman + stigma +1963\&ots = R9WkEt5JKk\&sig =EP_7ilmFK1DyoBz_JU-QbgX1rqg\#v $=$ onepage $\& q=$ goffman stigma 1963\&f = false Accessed July 17, 2017.

30. Berger BE, Ferrans CE, Lashley FR. Measuring stigma in people with HIV: psychometric assessment of the HIV stigma scale. Res Nurs Health. 2001;24:518-529.

31. Marshall PA. Ethical challenges in study design and informed consent for health research in resource-poor settings WHO Library Cataloguing-inPublication Data Ethical challenges in study design and informed consent for health research in resource-poor settings. http://apps.who.int/iris/ bitstream/10665/43622/1/9789241563383_eng.pdf Accessed July 6, 2017.

32. Onvomaha Tindana $P$, Kass N, Akweongo $P$. The informed consent process in a rural African setting: a case study of the Kassena-Nankana district of Northern Ghana. IRB. 2006;28:1-6.

33. Koita OA, Diallo A, Touré YT, et al. Informed consent in international research: the rationale for different approaches. Am J Trop Med Hyg. 2010;83:743-747.

34. Tekola F, Bull SJ, Farsides B, et al. Tailoring consent to context: designing an appropriate consent process for a biomedical study in a low income setting. King $\mathrm{CH}$, ed. PLoS Negl Trop Dis. 2009;3:e482.

35. National Institute on Drug Abuse (NIDA). Nationwide Trends. Drug Facts. 2015. www.drugabuse.gov/publications/drugfacts/nationwide-trends Accessed July 3, 2017.

36. Medley SG, Lipari RN, Bose J, International RTI, Cribb DS, Kroutil LA. Sexual orientation and estimates of adult substance use and mental health: results from the 2015 National Survey on Drug Use and Health. 2016. www.samhsa.gov/data/sites/default/files/NSDUH-SexualOrientation-2015/ NSDUH-SexualOrientation-2015/NSDUH-SexualOrientation-2015.pdf Accessed April 3, 2017.

37. Dirección Nacional de Control de Drogas. Ley 50-88 Sobre Drogas Y Sustancias Controladas. http://dncd.gob.do/content/uploads/03-Ley-50-88 sobre-Drogas-y-Sustancias-Controladas.pdf Accessed November 29, 2016.

38. Tomasini-Joshi D. No Health, No Help: Abuse as Drug Rehabilitation in Latin America and the Caribbean. 2016. www.opensocietyfoundations.org/sites/default/files/no-health-no-helpen-21060403.pdf Accessed June 7, 2017.

39. Budhwani $\mathrm{H}$, Turan $\mathrm{B}$, Hasbun J, et al. Association between violence exposure and condom non-use among transgender sex workers in the Dominican Republic: the mediating role of trust. Int J STD AIDS. 2017;28:608-612.

40. Reisner SL, Poteat T, Keatley J, et al. Global health burden and needs of transgender populations: a review. Lancet. 2016;388:412-436.

41. Winter S, Settle E, Wylie K, et al. Synergies in health and human rights: a call to action to improve transgender health. Lancet (London, England). 2016;388:318-321.

42. Wylie K, Knudson G, Khan SI, Bonierbale M, Watanyusakul S, Baral S. Serving transgender people: clinical care considerations and service delivery models in transgender health. Lancet (London, England). 2016;388:401-411.

Abbreviations Used
$\mathrm{Cl}=$ confidence interval
$\mathrm{COIN}=$ Centro de Orientación e Investigación Integral
$\mathrm{CONABIOS}=$ Consejo Nacional de Bioética en Salud
$\mathrm{FHI}=$ Family Health International
$\mathrm{MSM}=$ men who have sex with men
$\mathrm{OR}=$ odds ratios
$\mathrm{PEPFAR}=$ President's Emergency Plan for AIDS Relief's
$\mathrm{THNS}=$ Transgender Health Needs Study
$\mathrm{UNAIDS}=$ United Nations Programme on HIV/AIDS

Cite this article as: Budhwani $\mathrm{H}$, Hearld $\mathrm{KR}$, Milner AN, McGlaughlin $\mathrm{E}_{\text {, }}$ Charow R, Rodriguez-Lauzurique RM, Rosario S, Paulino-Ramirez R (2017) Transgender women's drug use in the Dominican Republic, Transgender Health 2:1, 188-194, DOI: 10.1089/trgh.2017.0032. 